Case Report

\title{
Midline cervical cleft: a case report
}

\section{Manivannan Dhanraj, Chetna Ravindra*, Maniselvi Swamidurai, Kannan Ross}

\author{
Institute of General Surgery, Madras Medical College, Chennai, Tamil Nadu, India
}

Received: 14 January 2020

Revised: 21 January 2020

Accepted: 22 January 2020

\author{
*Correspondence: \\ Dr. Chetna Ravindra, \\ E-mail: chetnaravindra@gmail.com
}

Copyright: ( ) the author(s), publisher and licensee Medip Academy. This is an open-access article distributed under the terms of the Creative Commons Attribution Non-Commercial License, which permits unrestricted non-commercial use, distribution, and reproduction in any medium, provided the original work is properly cited.

\begin{abstract}
A 14-year-old boy presented with complaints of a sinus in the middle of neck, with mucoid discharge present since birth. MRI sinogram along with MRI neck was taken which revealed a sinus tract opening in midline, extending posteriorly and traversing inferiorly to end blindly above sternum. Patient was planned for an elective excision of sinus tract, with z-plasty for decreased scarring. Congenital midline cervical cleft is a rare entity that was first described in 1924. Subsequently there have been fewer than 100 cases reported in medical literature. It typically manifests at birth as a cleft at level of suprasternal notch with a pseudonipple above it. Pathogenesis of congenital midline cervical clefts remains speculative. Differential diagnosis includes thyroglossal duct cysts or branchial cleft anomalies.
\end{abstract}

Keywords: Cervical cleft, Congenital defect, Midline neck lesion

\section{INTRODUCTION}

The most common diagnoses which come to mind when thinking of a midline neck lesion are dermoid cyst, thyroglossal duct cyst or lymphadenitis. Here we report a case of a patient presenting with a sinus over the midline of neck, present since childhood. It was clinically assumed to be a thyroglossal duct cyst, however these rarely present as a sinus, unless infected. ${ }^{1}$ Further evaluation revealed a branchial cleft anomaly, which generally present as lateral neck aberrations. However, in this case the defect was due to impaired fusion between arches of either side.

\section{CASE REPORT}

A 14-year-old boy presented with a small fissure over front of neck since birth which was gradually increasing in size with mucoid discharge from it. There was no history of pain. No history of trauma or previous surgeries was present. On examination, patient was conscious, oriented, afebrile, well-built and nourished. Vitals were stable. On local examination a linear fissure was seen vertically in anterior aspect of neck, of length 1 $\mathrm{cm}$. A small opening was present at its inferior aspect of size $1 \times 1 \mathrm{~mm}$, floor not made out. Mucoid discharge was present. At the superior aspect a globular swelling of size $7 \times 7 \mathrm{~mm}$ was present, with normal skin above. On palpation, no warmth or tender present, no induration felt about the fissure or external opening. The swelling at superior aspect was soft, non-fluctuant, noncompressible, non-transilluminant and immobile. No other swellings palpable in neck.

Hemogram, renal and liver function tests, serum electrolytes were within normal limits. X-ray sinogram revealed spread of contrast inferiorly - a sinus tract of length $2 \mathrm{~cm}$. Ultrasound scan of the neck confirmed a normal thyroid gland. MRI Neck showed a tract of length $1.8 \mathrm{~cm}$ extending downwards from external opening, traversing posteriorly in subcutaneous plane, ending 
blindly just above manubrium with a skin tag present at superior aspect.

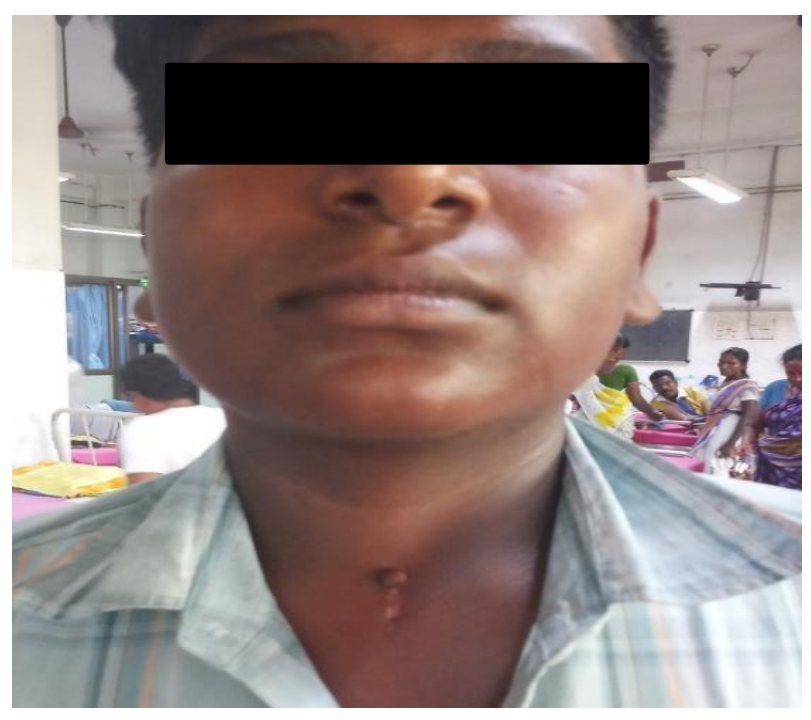

Figure 1: Clinical photo of patient with linear fissure and pseudonipple in midline.

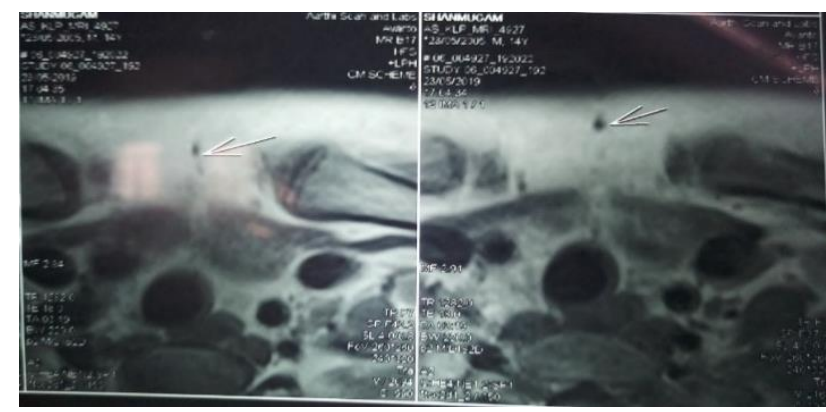

Figure 2: MRI showing T1 hypointense sinus in midline of neck.

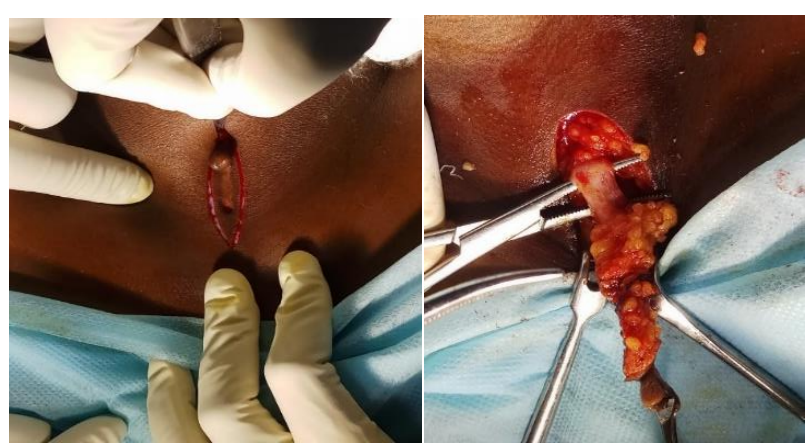

Figure 3: Excision of the lesion showing tract.

Patient was planned for an elective complete excision of the lesion. Elliptical incision made around entire fissure. Sinus tract identified traversing inferiorly and excised in entirety. Wound closed using Z-plasty. Post-operative period was uneventful.
Biopsy report showed a sinus tract lined by stratified squamous cells, devoid of any skin appendages. Inferior aspect of tract had seromucinous glands.

\section{DISCUSSION}

Congenital midline cervical cleft is a rare entity. It was first described in the English surgical literature by Bailey in $1924 .^{2}$ Subsequently, less than 100 cases have been described. A female to male ratio of $2: 1$ has been determined. ${ }^{3}$ Characteristic features are a defect at the ventral area of the neck with a nipple like projection at the upper part. ${ }^{4}$

Pathogenesis of the defect is an impaired fusion of the first or second branchial arches in the midline. There is also an improper interaction between the ectoderm and mesoderm at this point leading to lack of continuity of skin forming the fissure. May be associated with a thyroglossal duct cyst or a branchial cyst. ${ }^{1}$

Treatment involves surgical excision of the entire lesion. Left untreated in infancy, it may lead to contractures, maldevelopment of neck. Sometimes, it can lead to fibrosis and scar formation. There is also a possibility of infection of sinus leading to pain, erythema, increased discharge. If delayed, complications such as contractures and fibrous cords need to be addressed as well. ${ }^{5}$ A linear closure gives a higher risk of hypertrophic scar. Hence Zplasty is the accepted procedure being aesthetic and functional. All the cases described so far have presented in early neonatal and infancy period. Ours is the first case presenting in the second decade, without any associated complications.

Funding: No funding sources

Conflict of interest: None declared

Ethical approval: Not required

\section{REFERENCES}

1. Kakodkar K, Patel S, Maddalozzo J. Congenital midline cervical cleft. Otolaryngol. 2013:3(2)

2. Villanueva-Meyer J, Glastonbury C, Marcovici P. Congenital midline cervical cleft. J Radiol Case Rep. 2015;9(3):7-11.

3. Bahakim A, Francois M, Van Den Abbeele T. Congenital midline cervical cleft and w-plasty: our experience. Inter J Otolaryngol. 2018:2018.

4. Agag R, Sacks J, Silver L. Congenital midline cervical cleft. Cleft Palate Craniofac J. 2007;44(1):98-101.

5. Çelikoyar M, Aktan E, Doğusoy G. Congenital midline cervical cleft: a case report. J Med Case Reports. 2019;13:176.

Cite this article as: Dhanraj M, Ravindra C, Swamidurai M, Ross K. Midline cervical cleft: a case report. Int Surg J 2020;7:552-3. 